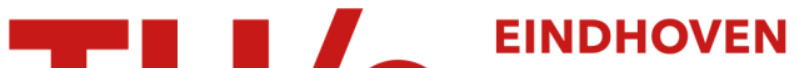 UNIVERSITY OF TECHNOLOGY
}

\section{Structure-property relationships of reactively compatibilized PHB/EVA/starch blends}

\section{Citation for published version (APA):}

Ma, P., Xu, P., Chen, M., Dong, W., Cai, X., Schmit, P., Spoelstra, A. B., \& Lemstra, P. J. (2014).

Structure-property relationships of reactively compatibilized PHB/EVA/starch blends. Carbohydrate Polymers, 108, 299-306. https://doi.org/10.1016/j.carbpol.2014.02.058

DOI:

10.1016/j.carbpol.2014.02.058

Document status and date:

Published: 01/01/2014

\section{Document Version:}

Publisher's PDF, also known as Version of Record (includes final page, issue and volume numbers)

\section{Please check the document version of this publication:}

- A submitted manuscript is the version of the article upon submission and before peer-review. There can be important differences between the submitted version and the official published version of record. People interested in the research are advised to contact the author for the final version of the publication, or visit the $\mathrm{DOI}$ to the publisher's website.

- The final author version and the galley proof are versions of the publication after peer review.

- The final published version features the final layout of the paper including the volume, issue and page numbers.

Link to publication

\section{General rights}

Copyright and moral rights for the publications made accessible in the public portal are retained by the authors and/or other copyright owners and it is a condition of accessing publications that users recognise and abide by the legal requirements associated with these rights.

- Users may download and print one copy of any publication from the public portal for the purpose of private study or research.

- You may not further distribute the material or use it for any profit-making activity or commercial gain

- You may freely distribute the URL identifying the publication in the public portal.

If the publication is distributed under the terms of Article 25fa of the Dutch Copyright Act, indicated by the "Taverne" license above, please follow below link for the End User Agreement:

www.tue.nl/taverne

Take down policy

If you believe that this document breaches copyright please contact us at:

openaccess@tue.nl

providing details and we will investigate your claim. 


\title{
Structure-property relationships of reactively compatibilized PHB/EVA/starch blends
}

\author{
P. Ma ${ }^{a, b, c, *}$, P. Xu ${ }^{a, b}$, M. Chen ${ }^{a, b}$, W. Dong ${ }^{a, b}$, X. Cai ${ }^{c, d}$, P. Schmit ${ }^{c}$, \\ A.B. Spoelstra ${ }^{\mathrm{c}}$, P.J. Lemstra ${ }^{\mathrm{c}}$ \\ a The Key Laboratory of Food Colloids and Biotechnology of Ministry of Education, 1800 Lihu Road, Wuxi 214122, China \\ b School of Chemical and Material Engineering, Jiangnan University, 1800 Lihu Road, Wuxi 214122, China \\ ${ }^{c}$ Department of Chemical Engineering and Chemistry, Eindhoven University of Technology, Eindhoven 5612 AZ, The Netherlands \\ d School of Food Science and Technology, Jiangnan University, 1800 Lihu Road, Wuxi 214122, China
}

\section{A R T I C L E I N F O}

\section{Article history:}

Received 12 January 2014

Received in revised form 15 February 2014

Accepted 17 February 2014

Available online 24 February 2014

\section{Keywords:}

Poly(hydroxybutyrate)

Poly(ethylene-co-vinyl acetate)

Starch

Morphology

Compatibilization

Property

\begin{abstract}
A B S T R A C T
A method is addressed to prepare poly(hydroxybutyrate)/poly(ethylene-co-vinyl acetate)/starch ( $\mathrm{PHB} / \mathrm{EVA} / \mathrm{starch}$ ) blends with fine dispersion of starch, i.e. by an in situ compatibilization in the presence of maleic anhydride (MA) and peroxide. The starch particle size is reduced from hundreds- $\mu \mathrm{m}$ to sub- $\mu \mathrm{m}$ after the compatibilization accompanied by an improvement in interfacial adhesion. Meanwhile, starch-in-EVA-type morphology is observed in the blends. The EVA and starch gradually changed into a (partially) co-continuous phase with increasing MA content. Consequently, toughness of the blends was improved as evidenced by an increase in elongation at break and tensile-fracture energy (work). Cavitation, fibrillation and matrix yielding are regarded as the toughening mechanism for the compatibilized blends. In addition, the $T_{g}$ of the EVA phase is dependent on its phase morphology in the blends while the thermal behavior of the PHB was only slightly affected by the compatibilization.
\end{abstract}

(c) 2014 Elsevier Ltd. All rights reserved.

\section{Introduction}

Poly(hydroxyalkanoates) (PHAs) are bio-based aliphatic polyesters produced by commonly found microorganisms as an energy storage mechanism. Poly(hydroxybutyrate)(PHB) is a wellknown member in the PHAs family. PHB has received considerable attention because of its renewability and biocompostability under both aerobic and anaerobic conditions (Srienc, Arnold, \& Bailey, 1984). However, it has not been widely applied yet as a commodity material due to the high price, poor processability and brittleness (Masayuki \& Keiichi, 2006; Pan \& Inoue, 2009).

Blending PHB with other (co-)polymers such as ethylenepropylene rubber (EPR) (Abbate, Martuscelli, Ragosta, \& Scarinzi, 1991), epoxidized natural rubber (ENR) (Parulekar \& Mohanty, 2006), poly(vinyl acetate) (PVAc) (Hay \& Sharma, 2000), poly( $\varepsilon$-caprolactone) (PCL) (Chun \& Kim, 2000), poly(butylene succinate) (PBS) (Ma, Hristova-Bogaerds, Lemstra, Zhang, \& Wang, 2012; Zhang, Mohanty, \& Misra, 2012), poly(butylene

\footnotetext{
* Corresponding author at: 1800 Lihu Road, Wuxi, China. Tel.: +86133 8288 8573; fax: +865108591 7763 .

E-mail address: p.ma@jiangnan.edu.cn (P. Ma).
}

adipate-co-terephthalate) (PBAT) (Nagarajan, Misra, \& Mohanty, 2013), poly(lactic acid) (PLA) (Gao et al., 2006; Kikkawa et al., 2006) and starch (Cheng, Peng, \& Lui, 2011) is an effective way to make bio-based materials with improved properties.

Among above (co-)polymers, starch is a renewable and compostable biopolymer which is derived from abundant natural sources such as potato, wheat and maize (Wurzburg, 1986). Starch would be an ideal alternative for oil-based polymers since it is even cheaper than oil. However, starch cannot be melt processed via conventional techniques because of severe thermal decomposition and too high molar mass (Liu, Xie, Yu, Chen, \& Li, 2009). To process starch, it has to be gelatinized and mixed with additives, e.g. plasticizers (Rodriguez-Gonzalez, Ramsay, \& Favis, 2004). The combination of gelatinized starch and additives is referred to as thermoplastic starch (TPS). Starch or TPS is usually used as filler in compounding with other polymers to reduce the "whitepollution" and carbon footprint (Cercle, Sarazin, \& Favis, 2013; Steller \& Meissner, 1998).

In recent years, the interest is focused on blending of starch with other biocompostable materials such as PHB (Don, Chung, Lai, \& Chiu, 2010; Ismail \& Gamal, 2010; Magalhães, Dahmouche, Lopes, \& Andrade, 2013; Reis et al., 2008; Xiong et al., 2013). The purpose is to reduce the cost of PHB-based materials while remaining 
the biocompostability and renewability. Whereas, the properties of $\mathrm{PHB} /$ starch blends are poor due to a lack of affinity between the two components (Reis et al., 2008). Although poly(vinyl acetate) (Don et al., 2010), nano-clay (Ismail \& Gamal, 2010), peroxide (Avella, Errico, Rimedio, \& Sadocco, 2002) and PHB-g-acrylic acid (Liao \& $\mathrm{Wu}, 2007$ ) could enhance the affinity between PHB and starch, the toughness of their blends was only improved to a certain extent.

It is known that PHB is miscible with poly(vinyl acetate) but immiscible with poly(ethylene) (Chang, Chou, \& Woo, 2011; ElTaweel, Stoll, \& Schick, 2011; Yoon, Oh, \& Kim, 1998). Hence, the compatibility between PHB and EVA can be tuned by the vinyl acetate (VA) content without the need for additional compatibilization. Moreover, EVA copolymers change from a semi-crystalline thermoplastic (PE) into a rubber and again into an amorphous thermoplastic (PVAC) with increasing the VA content. Therefore, the EVA copolymer could be an ideal modifier for the PHB/starch blends.

The primary objective of this paper is to achieve fine morphology and promising mechanical properties of PHB/EVA/starch blends via an in situ compatibilization. The structure and properties of the PHB/EVA/starch blend are studied in detail and the structure-property relationships are investigated.

\section{Experimental}

\subsection{Materials}

Poly(hydroxybutyrate) (Mirel ${ }^{\mathrm{TM}}$ M6000) was supplied by Metabolix, Inc. USA. It is a mixture of poly(3-hydroxybutyrate) and poly(3-hydroxybutyrate-co-4-hydroxybutyrate). The mixture shows single phase morphology since the two components are miscible, and is referred to as PHB in this paper. Gelatinized potato starch with $21 \mathrm{wt} \%$ amylose and $79 \mathrm{wt} \%$ amylopectin was supplied by Rodenburg Biopolymers B.V., The Netherlands. Before processing, the starch was dried over night in a vacuum oven at $50^{\circ} \mathrm{C}$. The $\mathrm{H}_{2} \mathrm{O}$ content in the dried starch was around $2 \mathrm{wt} \%$. Rubber grade EVA (Levapren ${ }^{\circledR} 500$ ) with vinyl acetate (VA) content of $50 \mathrm{wt} \%$ was supplied by Lanxess Chemical Co., Ltd. Maleic anhydride (MA) as a coupling agent was supplied by Fluka ${ }^{\circledR}$ with purity $\geq 99.0 \%$. Benzoyl peroxide (BPO) used as a free-radical grafting initiator was supplied by Aldrich ${ }^{\circledR}$ with a half-life time of approximately $1 \mathrm{~min}$ at $131^{\circ} \mathrm{C}$. Glycerol as a plasticizer for starch was supplied by Rodenburg Biopolymers B.V., The Netherlands. All the chemicals were used as received.

\subsection{Blend preparation}

The EVA pellets and starch with a weight ratio of 50/50 were first ground using a Retsch ZW100 grinder (14,000 rpm and mesh size of $0.5 \mathrm{~mm}$ ) to obtain a better pre-mixing with additives. Dry EVA/starch powders with designed amounts of glycerol, MA and BPO were blended on a twin-screw extruder $(D=16 \mathrm{~mm}, L / D=20)$ at $135^{\circ} \mathrm{C}$. A fixed screw rotation speed of $100 \mathrm{rpm}$ was used. Glycerol was used as a plasticizer of starch in this study. The PHB/EVA/starch blends were prepared by melt blending the EVA/starch precompounds with PHB in a home-built, recirculating, twin-screw mini-extruder at $175^{\circ} \mathrm{C}$ for $5 \mathrm{~min}$. A fixed screw speed of $90 \mathrm{rpm}$ was used. The extrudates of PHB/EVA/starch blends were pelletized and compression-molded using a compression molding machine (Collin Presse 300 G, Dr. Collin GmbH, Ebersberg, Germany) at $180^{\circ} \mathrm{C}$ for $2 \mathrm{~min}$ and then cold compression-molded for $15 \mathrm{~min}$. The final compression-molded sheets are around $0.8 \mathrm{~mm}$ in thickness, which were used for characterizations. The compositions of the final PHB/EVA/starch blends are listed in Table 1.

\subsection{Characterizations}

Scanning electron microscope (SEM): SEM (Quanta 600F-ESEM, FEI, the Netherlands) was used to characterize the morphology of the PHB/EVA/starch blends. The samples for phase morphology study were cut at $-80^{\circ} \mathrm{C}$ using a Leica Ultracut S/FCS microtome and sputter-coated with a thin gold layer before SEM observation. The gelatinized starch particles and the tensile fractured surfaces of the specimens were sputter-coated directly with a thin gold layer before SEM observation.

Transmission electron microscope (TEM): TEM was performed on the PHB/EVA/starch samples using a Tecnai 20 microscope, operated at $200 \mathrm{kV}$. Ultrathin sections $(\sim 70 \mathrm{~nm})$ were prepared at $-80^{\circ} \mathrm{C}$ using a Leica Ultracut S/FCS microtome with histo diamond knife. No staining was applied since the components have good electron density contrast.

Molau experiment: Molau experiment was done by dissolving $1.0 \mathrm{~g}$ of PHB/EVA/starch sample into $20 \mathrm{~mL}$ chloroform and sealed in glass bottles. Digital photos were taken after $48 \mathrm{~h}$ when the solution/emulsion was stabilized.

Mechanical properties: Tensile properties of the samples were measured by using a Zwick Z100 tensile tester at a crosshead speed of $10 \mathrm{~mm} / \mathrm{min}$. Five specimens of each sample are evaluated and the averaged results are presented. The narrow parallel-sided portion of the dumbbell-shaped tensile bar was $12 \mathrm{~mm}$ in length, $0.8 \mathrm{~mm}$ in thickness and $2 \mathrm{~mm}$ in width. The tests were carried out at room temperature.

Dynamic mechanical analysis (DMA): DMA was carried out on a DMA Q800 (TA Instruments, USA) with a tensile-film mode. The specimens $(13.0 \mathrm{~mm} \times 6.5 \mathrm{~mm} \times 0.8 \mathrm{~mm})$ were measured from -60 to $160^{\circ} \mathrm{C}$ with a frequency of $1 \mathrm{~Hz}$, an amplitude of $10 \mu \mathrm{m}$ and a temperature ramp of $3^{\circ} \mathrm{C} / \mathrm{min}$. The storage modulus and $\tan \delta$ were recorded as a function of temperature.

\section{Results and discussion}

The PHB/EVA/Starch blends were prepared via multi-step compounding, i.e. EVA and starch were reactively pre-compounded in the presence of maleic anhydride (MA), benzoyl peroxide (BPO) and glycerol, and the pre-compounds were subsequently blended with PHB.

\subsection{In situ compatibilization in the EVA/Starch blends}

Native potato starch in the form of granules exhibits high crystalline order. The diameter of granules ranges from 15 to $70 \mu \mathrm{m}$ (Ma, Hristova-Bogaerds, Schmit, Goossens, \& Lemstra, 2012c). The crystal structure can be destroyed by a so-called gelatinization in the presence of heat, shear and plasticizer(s) (e.g. $\mathrm{H}_{2} \mathrm{O}$ ). An increase in particle size is obtained due to agglomerations in the gelatinization process. Gelatinized starch is easier to process in comparison with native starch and is thus used in this work. A SEM image of the gelatinized starch is shown in Fig. $1 \mathrm{a}$.

The phase morphology of starch-related blends is usually coarse because of the high molecular mass, strong hydrogen bonds and hydrophilic nature of starch. Fine morphology is required for good mechanical properties. In this part, in situ compatibilization via maleic anhydride (MA) is applied to tune the morphology of the $\mathrm{EVA} /$ starch blends. The effect of the compatibilization on the phase morphology of the blends is shown in Fig. 1b and c.

The starch particles are non-uniformly dispersed in the EVA matrix with large sizes (from 50 to $250 \mu \mathrm{m}$ ) in the absence of MA, as shown in Fig. 1b. The size is comparable to that of neat starch (Fig. 1a). It implies that the starch particles were almost not brokenup during blending, or the starch particles agglomerated after 
Table 1

Compositions of the PHB/EVA/starch/glycerol/MA/BPO blends.

\begin{tabular}{|c|c|c|c|c|c|c|}
\hline Sample code & PHB (wt\%) & EVA (wt\%) & Starch (wt\%) & Glycerol (wt\%) & MA (wt\%) & $\mathrm{BPO}$ (wt\%) \\
\hline $1 \#$ & - & 45.5 & 45.5 & 9.0 & 0.00 & 0.000 \\
\hline $2 \#$ & - & 45.5 & 45.5 & 9.0 & 0.23 & 0.023 \\
\hline $3 \#$ & - & 45.0 & 45.0 & 9.0 & 0.45 & 0.045 \\
\hline $4 \#$ & - & 45.0 & 45.0 & 9.0 & 0.90 & 0.090 \\
\hline $5 \#$ & 60.0 & 18.2 & 18.2 & 3.6 & 0.00 & 0.000 \\
\hline $6 \#$ & 60.1 & 18.1 & 18.1 & 3.6 & 0.09 & 0.009 \\
\hline $7 \#$ & 60.0 & 18.1 & 18.1 & 3.6 & 0.18 & 0.018 \\
\hline $8 \#$ & 60.0 & 18.0 & 18.0 & 3.6 & 0.36 & 0.036 \\
\hline
\end{tabular}

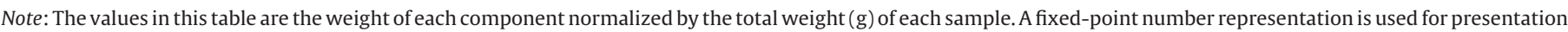
thus in total it is roughly but not accurately $100 \mathrm{wt} \%$. The spread for the composition of PHB, EVA and starch is $<0.2 \mathrm{wt} \%$.

breaking-up. In addition, large cavities left by the starch particles are observed showing a poor interfacial adhesion between the two components. Interestingly, starch particles in sub- $\mu \mathrm{m}$ scale are uniformly dispersed in the EVA matrix in the presence of MA (Fig. 1c).

MA could be grafted onto EVA chains via a free radical grafting mechanism, while esterification reactions occur between the grafted MA and the hydroxyl groups of starch chains (Kim, Shin, Hong, Cho, \& Ha, 2001; Wang, Liu, \& Xiong, 2007; Zhang \& Sun, 2004). The reaction between EVA and starch via MA and BPO was confirmed by IR characterization resulting in EVA-g-starch copolymers, as shown in Fig. 1d and reported previously (Ma, Hristova-Bogaerds, \& Goossens, et al., 2012). The presence of glycerol reduces the viscosity of starch leading to a reduction in the critical capillary number $\left(\mathrm{Ca}_{\text {crit }}\right)$ of the blend. As a result, starch particles with glycerol could break up more efficiently in a shear field, offering larger interfaces. The EVA-g-starch copolymers are then generated in situ at the interfaces preventing agglomeration of fine starch particles. Consequently, fine morphology of the blends is obtained, e.g. the size of starch particles is reduced by a factor of around 100 .

\subsection{Morphology of the PHB/EVA/starch blends in the presence of} $M A$

The effect of MA concentration on the morphology of the PHB/EVA/starch blends is studied by using SEM, as shown in Fig. 2. In the absence of MA, large starch particles are observed in the PHB matrix (Fig. 2a), while EVA exist as fine domains (Fig. 2a'). Interfacial debonding between the PHB and starch is visible indicating a poor affinity. The starch particle size is reduced after addition of
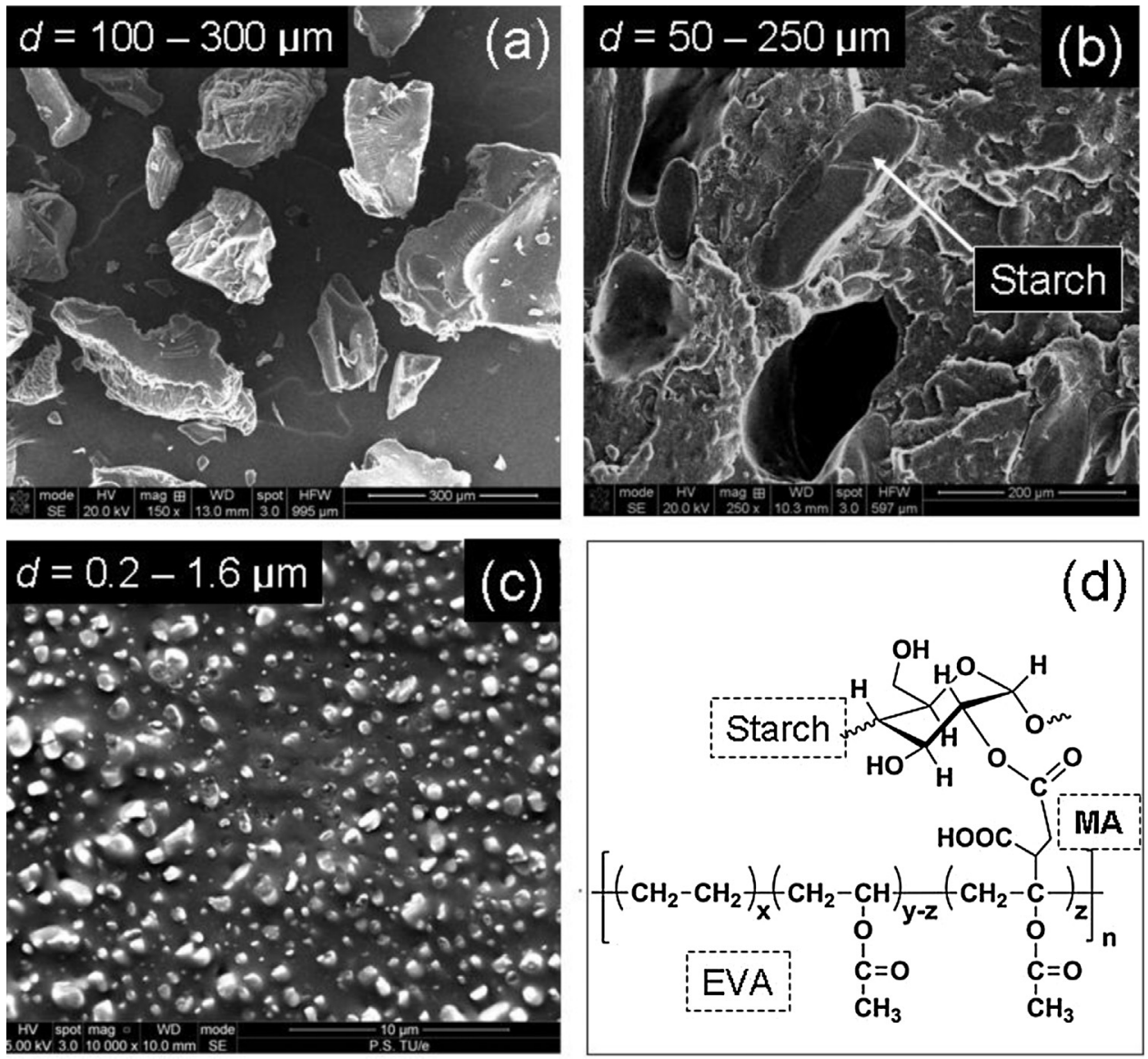

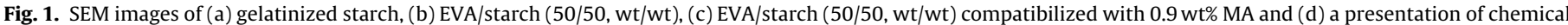

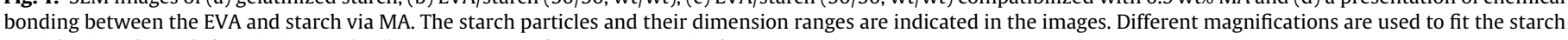
particle size. The scale bars in images $(\mathrm{a}-\mathrm{c})$ are 300,200 and $10 \mu \mathrm{m}$, respectively. 

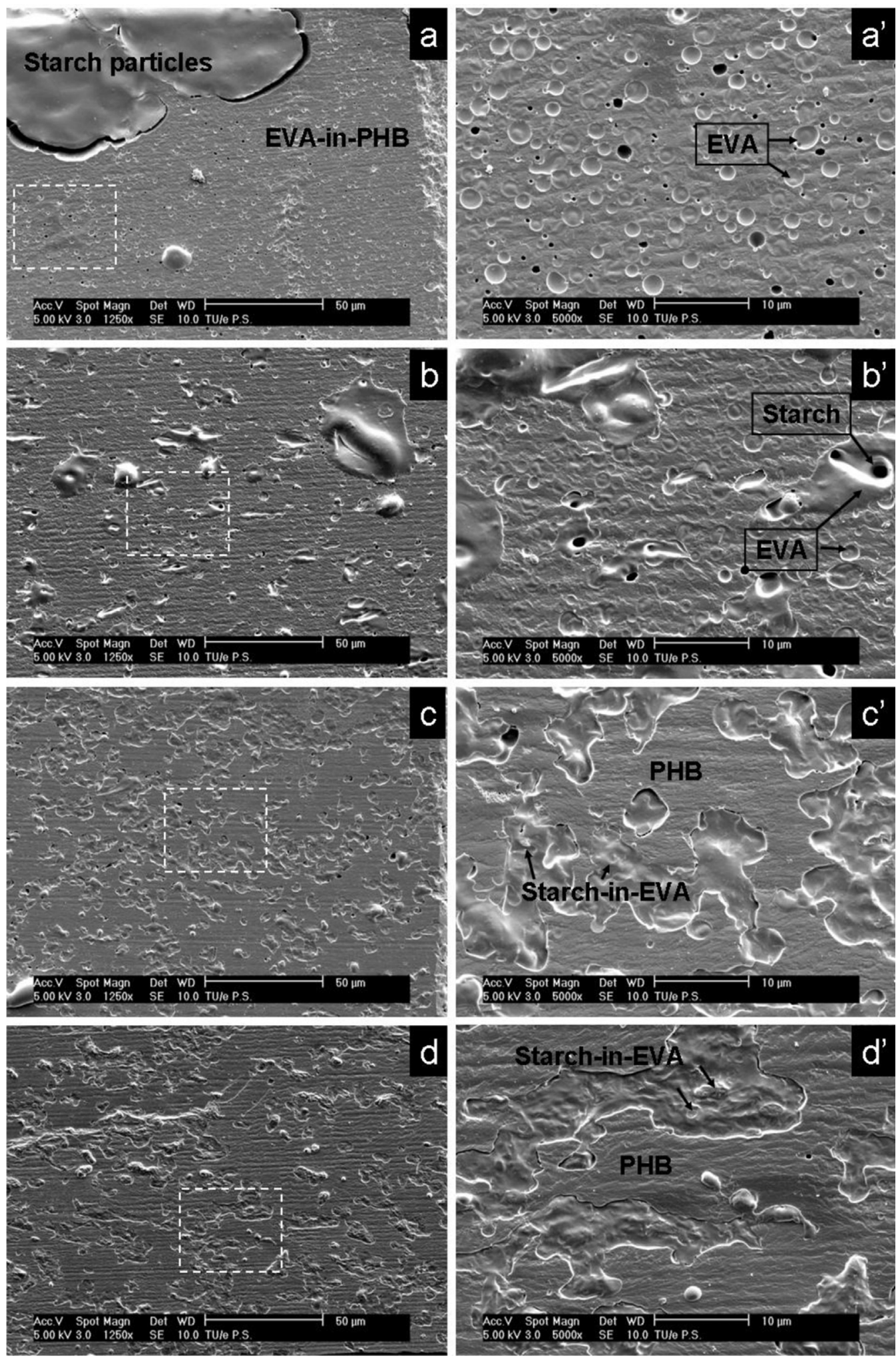

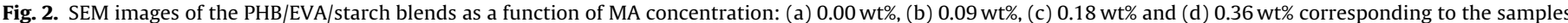
$5 \#-8 \#$ respectively. The surfaces were cryo-microtomed with a diamond knife. The rectangle regions in images a-d are magnified as images a' $-\mathrm{d}^{\prime}$, respectively.

0.09 wt\% MA (Fig. 2b). Some starch particles are capsulated in EVA phase while a lot of EVA fine domains are still embedded in the PHB matrix (Fig. 2b'). Interestingly, the starch was "migrated" from the PHB matrix into the EVA phase when the MA content is increased to $0.18 \mathrm{wt} \%$ and $0.36 \mathrm{wt} \%$. Moreover, an interpenetrating or (partially) co-continuous starch-in-EVA-type morphology is obtained (Fig. 2c and d). The interface between the fine starch particles and the EVA is indistinct demonstrating a strong interfacial adhesion (Fig. $2 \mathrm{C}^{\prime}$ and $\mathrm{d}^{\prime}$ ).

Such changes in morphology are attributed to an emulsifying effect of the EVA-g-starch copolymers. The emulsifying effect is confirmed by Molau experiments (Molau, 1965), as shown in Fig. 3. 


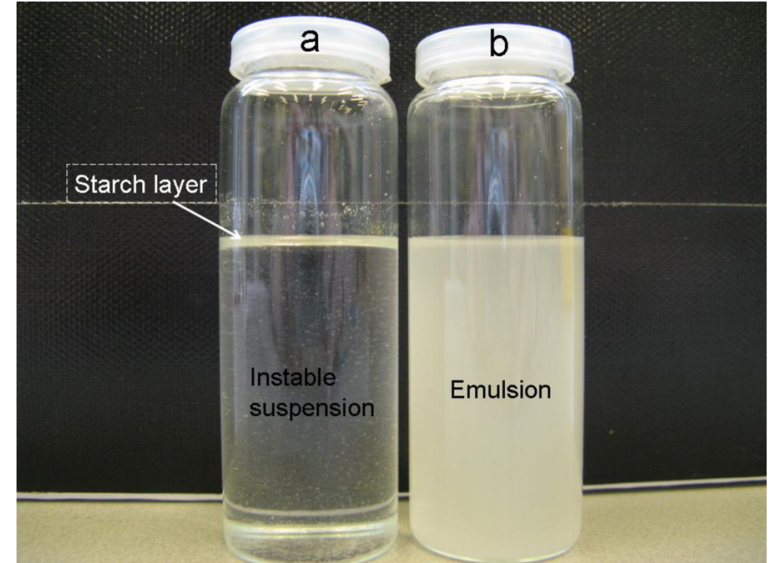

Fig. 3. A digital image of the PHB/EVA/starch blends in chloroform: (a) without compatibilization and (b) after in situ compatibilization with $0.36 \mathrm{wt} \% \mathrm{MA}$.

Since no chemical bonding between starch and the other components in the absence of MA, both PHB and EVA are dissolved in chloroform leaving starch particles on the top layer of the solution (Fig. 3a). The grafted EVA chains can also be dissolved while they are chemically bonded on the surfaces of starch particles preventing the agglomeration and precipitation of fine starch particles in the emulsion. Consequently, stable emulsion is obtained, as shown in Fig. 3b. It has to be remarked that no obvious gelation was observed in the examined samples probably due to the low BPO concentration ( $<0.09 \mathrm{wt} \%$ in EVA/Starch blends).

TEM is performed on the compatibilized PHB/EVA/starch blend to provide a deeper insight in the starch-in-EVA-type (or core-shell-like) morphology, as shown in Fig. 4. PHB is the matrix. The bright domains correspond to starch particles while the dark contrast around starch particles represents the EVA phase, as noted in Fig. 4. Clearly, starch particles with sub- $\mu \mathrm{m}$ dimension are mainly embedded in the EVA phase and some EVA particles in combination with starch are interconnected.

\subsection{Dynamic mechanical properties and thermal behavior of the PHB/EVA/starch blends}

Storage modulus $\left(E^{\prime}\right)$ and $\tan \delta$ of the PHB/EVA/starch blends are shown in Fig. 5 as a function of temperature. The blends have similar $E^{\prime}$ values in the glassy state $\left(<-40^{\circ} \mathrm{C}\right)$. PHB is rigid at room temperature $\left(E^{\prime} \mathrm{PHB}-23^{\circ} \mathrm{C}=1500 \mathrm{MPa}\right)$ while EVA is rubbery

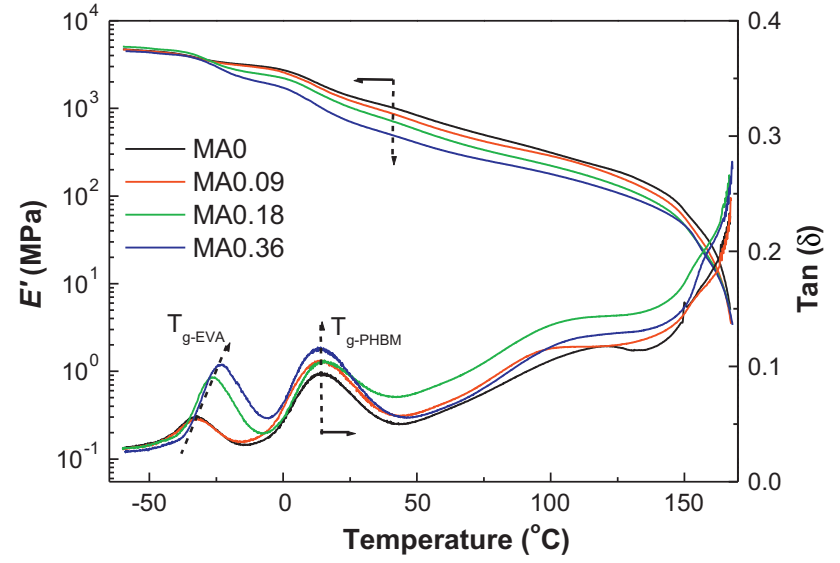

Fig. 5. Storage modulus $\left(E^{\prime}\right)$ and $\tan \delta$ of the PHB/EVA/starch blends as a function of MA content and temperature. $T_{g \text {-EVA }}$ and $T_{g \text {-PHB }}$ represent the glass transition temperatures of the EVA and PHB phases, respectively.

( $E^{\prime} \mathrm{EVA}-23{ }^{\circ} \mathrm{C}=3 \mathrm{MPa}$ ), thus the $E^{\prime}$ at room temperature is dominated by PHB as long as PHB is the continuous phase. As discussed above, the EVA with starch gradually changes from a dispersed phase into a (partially) co-continuous phase with increasing MA content. The larger EVA/starch domains or (partially) continuous EVA/starch phase result in a reduction in the $E^{\prime}$ values at room temperatures. The $E^{\prime}$ of all the blends decreases slightly at around -30 and $14{ }^{\circ} \mathrm{C}$ due to the glass transitions of the EVA and PHB phases respectively, and drops steeply at around $160^{\circ} \mathrm{C}$ being ascribed to the melt of PHB matrix.

The $\tan \delta$ peak temperatures are referred to as glass transition temperatures $\left(T_{g}\right)$ of corresponding components, as shown in Fig. 5. The $T_{g}$ of thermoplastic starch (TPS) was reported to be between -8 and $50^{\circ} \mathrm{C}$, however, it was seldom detected by DSC or DMTA (Lourdin, Bizot, \& Colonna, 1997; Orozco, Brostow, Chonkaew, \& Lopez, 2009; Wan, Sun, \& Seib, 2002; Wang, Yu, \& Ma, 2007; Wang, Yu, \& Ma, 2008). The $T_{g}$ of PHB in the blends keeps constant with MA content. The $T_{g}$ of neat EVA is $-20^{\circ} \mathrm{C}$ (not shown here) which is decreased to $-32{ }^{\circ} \mathrm{C}$ after fine dispersed in the PHB (MA0, Fig. 5). Interestingly, the $T_{g}$ of EVA $\left(T_{g \text {-EVA }}\right)$ in the blends is increased at high MA content, e.g. increased by $9^{\circ} \mathrm{C}$ at $0.36 \mathrm{wt} \% \mathrm{MA}$. The increase in $T_{g \text {-EVA }}$ is associated with composition variety of the EVA domains due to the partial miscibility between PHB and EVA and the changes in phase morphology (Ma, 2011, chap. 6). A third relaxation temperature around $100^{\circ} \mathrm{C}$ is also detected. It might refer to the starch
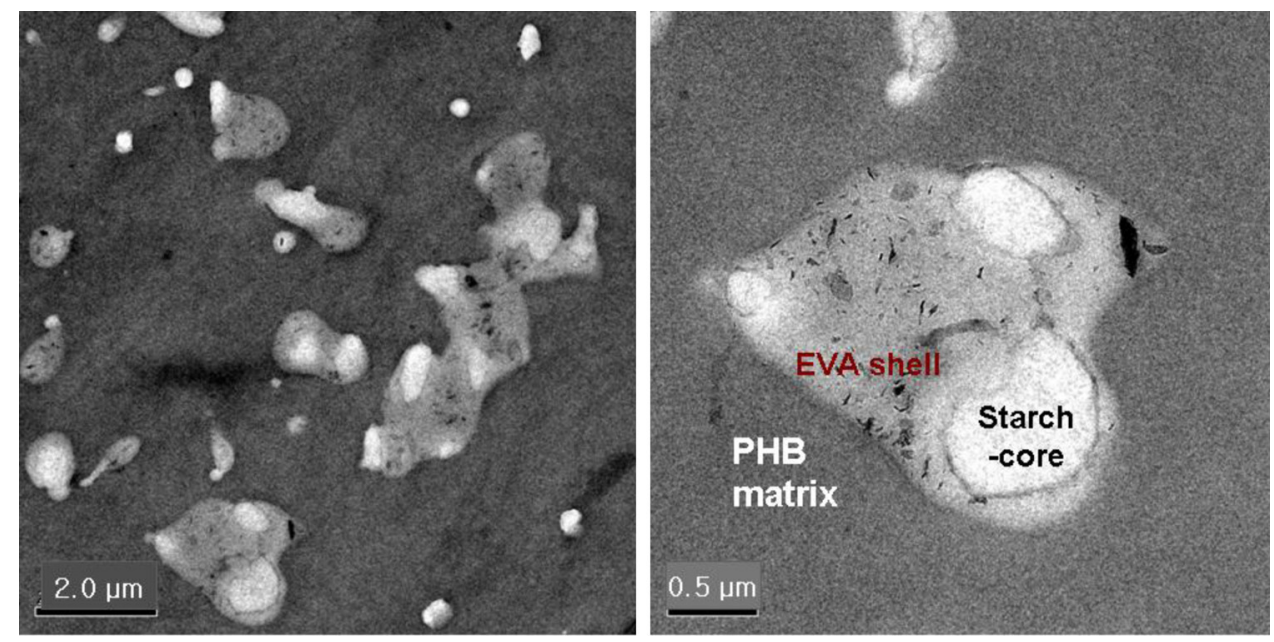

Fig. 4. TEM images of the in situ compatibilized PHB/EVA/starch blend (sample 8\#). 
(a)

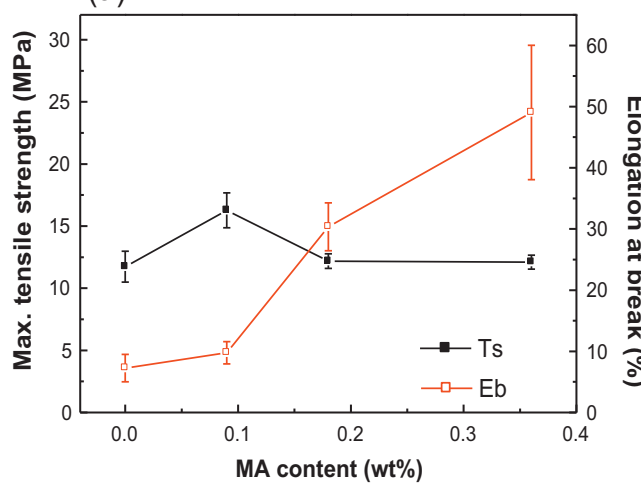

(c)

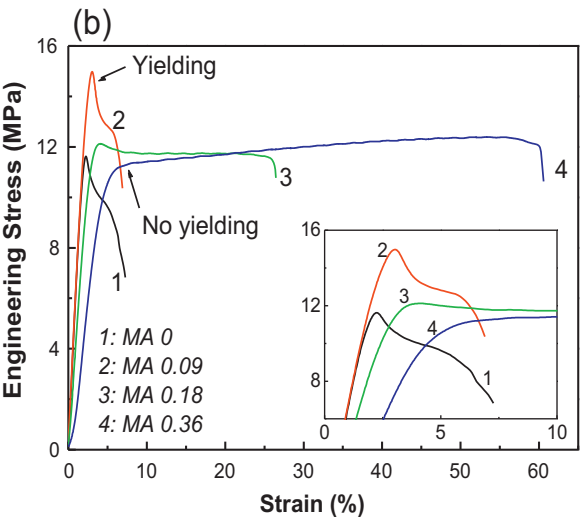

Strain (\%)

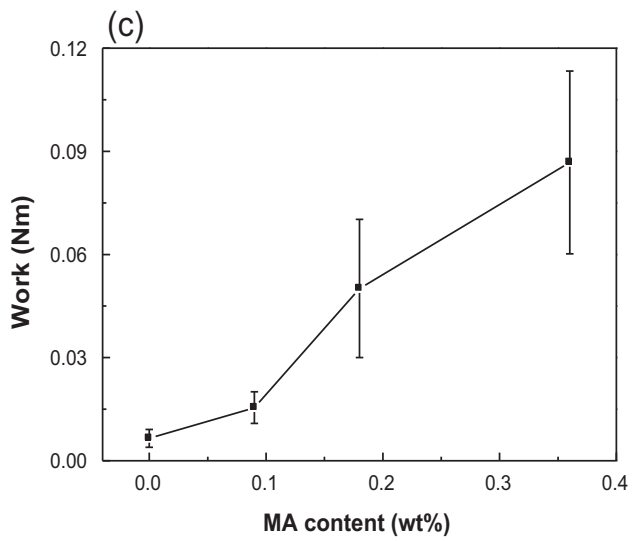

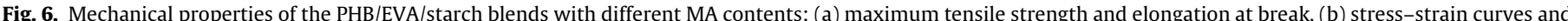
(c) energy absorption during tensile process (work).
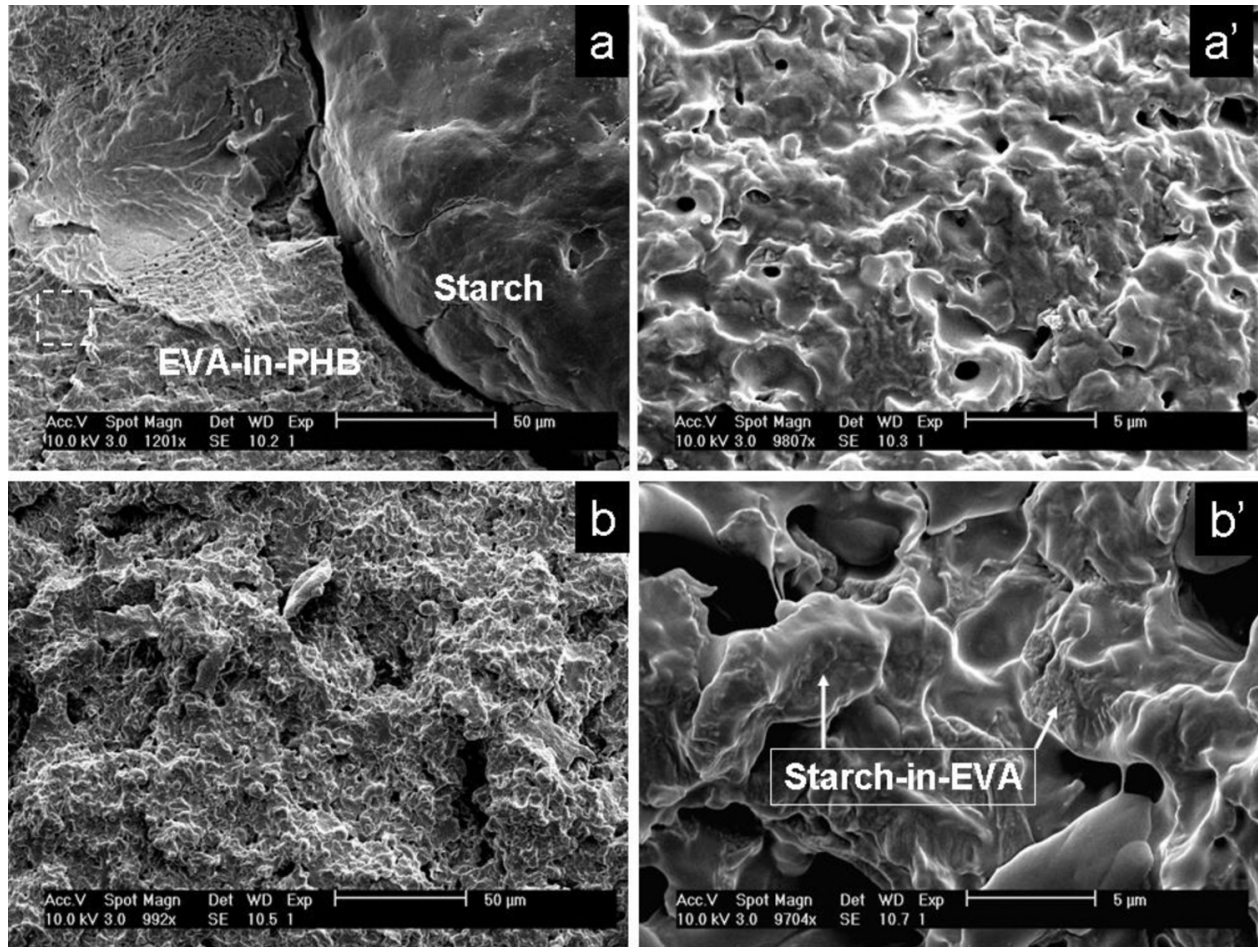

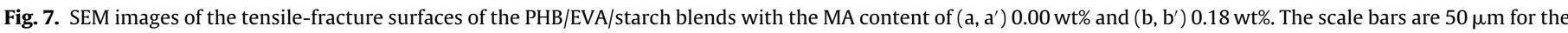
images $\mathrm{a} / \mathrm{b}$ and $5 \mu \mathrm{m}$ for the images $\mathrm{a}^{\prime} / \mathrm{b}^{\prime}$. Image $\mathrm{a}^{\prime}$ corresponds to the rectangle region in image $\mathrm{a}$. 
phase in the presence of water since no such relaxation processes were observed in the case of PHB and EVA, which has to be confirmed further.

\subsection{Mechanical properties of the PHB/EVA/starch blends}

Mechanical properties of the PHB/EVA/starch blends were studied by using a tensile tester, as shown in Fig. 6. The maximum tensile strength first increases with the MA content and then decreases and levels off (Fig. 6a). On the other hand, the elongation at break increases monotonically with the MA content. The variety of properties relates to the phase-morphology. The highest tensile strength is observed at $0.09 \mathrm{wt} \% \mathrm{MA}$ (Fig. 6a) due to both the small starch particles and the fine dispersion of EVA domains (Fig. 2b). When the MA content is higher than $0.18 \mathrm{wt} \%$, EVA with starch forms an interpenetrating or (partially) co-continuous phase which has lower tensile strength but higher elongation at break than the PHB. As a result, lower tensile strength and higher elongation at break of the ternary blends is obtained at high MA content.

Fig. 6b shows the typical stress-strain curves of the $\mathrm{PHB} / \mathrm{EVA} /$ starch blends. The blends show notable yielding behavior when the MA content is $\leq 0.09 \mathrm{wt} \%$, but fail after yielding. On the other hand, the blends with 0.18 and 0.36 wt\% MA underwent colddrawn processes accompanied by stress-whitening of the tensile bars, showing ductile behavior. The yielding phenomenon becomes less and less pronounced with the MA content up to $0.36 \mathrm{wt} \%$, which is attributed to the existence of (partially) continuous elastomeric phase referring to the EVA/starch components (Fig. 2c and d).

The area under stress-strain curves, namely work or energy dissipated during tensile process, can be used to evaluate the toughness of a material (Chen \& Evans, 2009; Monette, Anderson, \& Grest, 1993). The work of each PHB/EVA/starch specimen was recorded automatically by the tensile tester and summarized in Fig. 6c. Apparently, the work increases with the MA content, indicating that the (tensile) toughness of the blends is enhanced by the in situ compatibilization.

\subsection{Toughening mechanism of the PHB/EVA/starch blends}

It would be of interest to study the toughening mechanism since the toughness of PHB/EVA/starch blends is enhanced after the in situ compatibilization. The effect of in situ compatibilization on the toughness is explained via analysis of the tensile-fracture surfaces, as shown in Fig. 7.

Large starch particles are observed on the tensile-fracture surfaces of the non-compatibilized blends, as shown in Fig. 7a. The starch particles have smooth surfaces and debond from the PHB matrix, indicating rather poor interfacial adhesion. However the PHB matrix with fine EVA domains (also see Fig. 2a and $a^{\prime}$ ) undergoes plastic deformation, as shown in Fig. $7 a^{\prime}$. These results display that the PHB matrix is toughened by the EVA whereas the toughness of the PHB/EVA/starch blends is compromised by the large starch particles and the poor affinity between the starch and the PHB matrix. On the other hand, the tensile-fracture surfaces of the in situ compatibilized blends exhibit uniform morphology because of fine starch particles in the EVA phase. It is observed that plastic deformation of the matrix, cavitation and fibrillation occurred on the fracture surfaces of the compatibilized blends (Fig. 7b/b') which are mainly responsible for the improved tensile toughness.

\section{Conclusions}

Dispersion of starch in hydrophobic polymers is an issue because of its high molecular mass, strong hydrogen bonds and hydrophilic nature. In this work, PHB/EVA/starch blends with fine dispersion of starch were obtained via multi-step processing techniques. In situ compatibilization via maleic anhydride (MA) and benzoyl peroxide (BPO) was applied between the EVA and starch components. Consequently, EVA/starch pre-compounds were prepared with sub- $\mu \mathrm{m}$ scale starch particles $(d=0.2-1.6 \mu \mathrm{m})$ and strong interfacial adhesion. Since EVA was chemically bonded with starch, no obvious agglomeration of the starch particles occurred during the subsequent compounding with PHB. Thus, the fine morphology of starch was remained in the $\mathrm{PHB} / \mathrm{EVA} /$ starch blends. Molau experiments display that the compatibilized PHB/EVA/starch blends in chloroform can form stable emulsion due to the emulsifying effect of EVA-g-starch copolymers. Starch-in-EVA-type (or core-shell-like) morphology was observed in the PHB/EVA/starch blends. Moreover, the EVA in combination with starch gradually forms (partially) co-continuous phase with the MA content up to $0.36 \mathrm{wt} \%$. The presence of grafted EVA not only stabilized the fine morphology but also improved the toughness of the blends as evidenced by an increase in elongation at break and tensile-fracture energy (work). The toughening mechanism for the in situ compatibilized blends is regarded as cavitation, fibrillation and matrix yielding. In addition, the glass transition temperature of EVA is dependent on its phase morphology in the PHB matrix while the thermal behaviors of the PHB in the blends are not affected obviously by the in situ compatibilization.

\section{Acknowledgements}

This work is supported by the National Natural Science Foundation of China (51303067), the Natural Science Foundation of Jiangsu Province (BK20130147).

\section{References}

Abbate, M., Martuscelli, E., Ragosta, G., \& Scarinzi, G. (1991). Tensile properties and impact behaviour of poly(D(-)3-hydroxybutyrate)/rubber blends. Journal of Materials Science, 26, 1119-1125.

Avella, M., Errico, M. E., Rimedio, R., \& Sadocco, P. (2002). Preparation of biodegradable polyesters/high-amylose-starch composites by reactive blending and their characterization. Journal of Applied Polymer Science, 83, 1432-1442.

Cercle, C., Sarazin, P., \& Favis, B. D. (2013). High performance polyethylene/thermoplastic starch blends through controlled emulsification phenomena. Carbohydrate Polymers, 92, 138-148.

Chang, L., Chou, Y. H., \& Woo, E. M. (2011). Effects of amorphous poly(vinyl acetate) on crystalline morphology of poly(3-hydroxybutyric acid-co-3-hydroxyvaleric acid). Colloid and Polymer Science, 289, 199-211.

Chen, B., \& Evans, J. R. (2009). Impact strength of polymer-clay nanocomposites. Soft Matter, 5, 3572-3584.

Cheng, W. Y., Peng, J., \& Lui, W. B. (2011). Effects of $\alpha$-amylase and glycerol levels on the composition optimization of poly( $\beta$-hydroxybutyrate-co-valerate)/starch blended biodegradable resin analyzed with response surface methodology.Journal of Applied Polymer Science, 120, 2571-2578.

Chun, Y. S., \& Kim, W. N. (2000). Thermal properties of poly(hydroxybutyrate-cohydroxyvalerate) and poly ( $\varepsilon$-caprolactone) blends. Polymer, 41, 2305-2308.

Don, T. M., Chung, C. Y., Lai, S. M., \& Chiu, H. J. (2010). Preparation and properties of blends from poly(3-hydroxybutyrate) with poly(vinyl acetate)-modified starch. Polymer Engineering \&' Science, 50, 709-718.

El-Taweel, S. H., Stoll, B., \& Schick, C. (2011). Crystallization kinetics and miscibility of blends of polyhydroxybutyrate (PHB) with ethylene vinyl acetate copolymers (EVA). e-Polymer, 18, 1-16.

Gao, Y., Kong, L., Zhang, L., Gong, Y., Chen, G., Zhao, N., et al. (2006). Improvement of mechanical properties of poly(DL-lactide) films by blending of poly(3-hydroxybutyrate-co-3-hydroxyhexanoate). European Polymer Journal, $42,764-775$.

Hay, J. N., \& Sharma, L. (2000). Crystallisation of poly(3-hydroxybutyrate)/poly(vinyl acetate) blends. Polymer, 41, 5749-5757

Ismail, A. M., \& Gamal, M. A. B. (2010). Water resistance, mechanical properties, and biodegradability of poly(3-hydroxybutyrate)/starch composites. Journal of Applied Polymer Science, 115, 2813-2819.

Kikkawa, Y., Suzuki, T., Tsuge, T., Kanesato, M., Doi, Y., \& Abe, H. (2006). Phase structure and enzymatic degradation of poly(L-lactide)/atactic poly(3hydroxybutyrate) blends: An atomic force microscopy study. Biomacromolecules, 7, 1921-1928.

Kim, S. J., Shin, B. S., Hong, J. L., Cho, W. J., \& Ha, C. S. (2001). Reactive compatibilization of the PBT/EVA blend by maleic anhydride. Polymer, 42, 4073-4080

Liao, H. T., \& Wu, C. S. (2007). Performance of an acrylic-acid-grafted poly(3-hydroxybutyric acid)/starch bio-blend: Characterization and physical properties. Designed Monomers and Polymers, 10, 1-18. 
Liu, H., Xie, F., Yu, L., Chen, L., \& Li, L. (2009). Thermal processing of starch-based polymers. Progress in Polymer Science, 34, 1348-1368.

Lourdin, D., Bizot, H., \& Colonna, P. (1997). "Antiplasticization” in starch-glycerol films? Journal of Applied Polymer Science, 63, 1047-1053.

Ma, P. (2011). Tailoring the properties of bio-based and biocompostable polymer blends. Eindhoven, the Netherlands: Ipskamp Drukkers Printer.

Ma, P., Hristova-Bogaerds, D. G., Lemstra, P. J., Zhang, Y., \& Wang, S. (2012). Toughening of PHBV/PBS and PHB/PBS blends via in situ compatibilization using dicumyl peroxide as a free-radical grafting initiator. Macromolecular Materials and Engineering, 297, 402-410.

Ma, P., Hristova-Bogaerds, D. G., Goossens, J. G. P., Spoelstra, A. B., Zhang, Y., \& Lemstra, P. J. (2012). Toughening of poly(lactic acid) by ethylene-co-vinyl acetate copolymer with different vinyl acetate contents. European Polymer Journal, 48, 146-154.

Ma, P., Hristova-Bogaerds, D. G., Schmit, P., Goossens, J. G. P., \& Lemstra, P. J. (2012). Reactive compatibilization of ethylene-co-vinyl acetate/starch blends. Macromolecular Research, 20, 1054-1062.

Magalhães, N. F., Dahmouche, K., Lopes, G. K., \& Andrade, C. T. (2013). Using an organically modified montmorillonite to compatibilize a biodegradable blend. Applied Clay Science, 72, 1-8.

Masayuki, Y., \& Keiichi, A. (2006). Effect of thermal degradation on rheological properties for poly(3-hydroxybutyrate). European Polymer Journal, 42, 1479-1486.

Molau, G. E. (1965). Heterogeneous polymer systems. I. Polymeric oil-in-oil emulsions. Journal of Polymer Science Part A: Polymer Chemistry, 3, 1267-1278.

Monette, L., Anderson, M. P., \& Grest, G. S. (1993). Effect of interphase modulus and cohesive energy on the critical aspect ratio in short-fibre composites. Journal of Materials Science, 28, 79-99.

Nagarajan, V., Misra, M., \& Mohanty, A. K. (2013). New engineered biocomposites from poly(3-hydroxybutyrate-co-3-hydroxyvalerate) (PHBV)/poly(butylene adipate-co-terephthalate) (PBAT) blends and switch grass: Fabrication and performance evaluation. Industrial Crops and Products, 42, 461-468.

Orozco, V. H., Brostow, W., Chonkaew, W., \& Lopez, B. L. (2009). Preparation and characterization of poly(lactic acid)-g-maleic anhydride/starch blends. Macromolecular Symposia, 277, 69-80.

Pan, P., \& Inoue, Y. (2009). Polymorphism and isomorphism in biodegradable polyesters. Progress in Polymer Science, 34, 605-640.

Parulekar, Y., \& Mohanty, A. K. (2006). Biodegradable toughened polymers from renewable resources: Blends of polyhydroxybutyrate with epoxidized natural rubber and maleated polybutadiene. Green Chemistry, 8, 206-213.
Reis, K. C. Pereira, J., Smith, A. C., Carvalho, C. W. P., Wellner, N., \& Yakimets, I. (2008). Characterization of polyhydroxybutyrate-hydroxyvalerate (PHB-HV)/maize starch blend films. Journal of Food Engineering, 89, 361 369.

Rodriguez-Gonzalez, F. J., Ramsay, B. A., \& Favis, B. D. (2004). Rheological and thermal properties of thermoplastic starch with high glycerol content. Carbohydrate Polymers, 58, 139-147.

Srienc, F., Arnold, B., \& Bailey, J. E. (1984). Characterization of intracellular accumulation of poly-beta-hydroxybutyrate (PHB) in individual cells of Alcaligenes eutrophus H16 by flow cytometry. Biotechnology and Bioengineering, 26 982-987.

Steller, R., \& Meissner, W. (1998). Structure and properties of degradable polyolefinstarch blends. Polymer Degradation and Stability, 60, 471-480.

Wang, N., Yu, J., \& Ma, X. (2007). Preparation and characterization of thermoplastic starch/PLA blends by one-step reactive extrusion. Polymer International, 56 1440-1447

Wang, N., Yu, J., \& Ma, X. (2008). Preparation and characterization of compatible thermoplastic dry starch/poly(lactic acid). Polymer Composite, 29, 551559.

Wang, T., Liu, D., \& Xiong, C. (2007). Synthesis of EVA-g-MAH and its compatibilization effect to PA11/PVC blends. Journal of Materials Science, 42, 3398-3407.

Wan, H., Sun, X., \& Seib, P. (2002). Mechanical properties of poly(lactic acid) and wheat starch blends with methylenediphenyl diisocyanate. Journal of Applied Polymer Science, 84, 1257-1262.

Wurzburg, O. B. (1986). Modified starches: Properties and uses. Boca Raton, FL: CRC Press, Inc

Xiong, Z., Li, C., Ma, S., Feng, J., Yang, Y., Zhang, R., et al. (2013). The properties of poly(lactic acid)/starch blends with a functionalized plant oil: Tung oil anhydride. Carbohydrate Polymers, 95, 77-84.

Yoon, J. S., Oh, S. H., \& Kim, M. N. (1998). Compatibility of poly(3 hydroxybutyrate)/poly(ethylene-co-vinyl acetate) blends. Polymer, 39 $2479-2487$.

Zhang, J. F., \& Sun, X. (2004). Mechanical properties of poly(lactic acid)/starch composites compatibilized by maleic anhydride. Biomacromolecules, 5, 1446 1451.

Zhang, K., Mohanty, A. K., \& Misra, M. (2012). Fully Biodegradable and biorenewable ternary blends from polylactide, poly(3-hydroxybutyrate-co-hydroxyvalerate) and poly(butylene succinate) with balanced properties. ACS Applied Materials $\mathcal{E}$ Interfaces, 4, 3091-3101. 